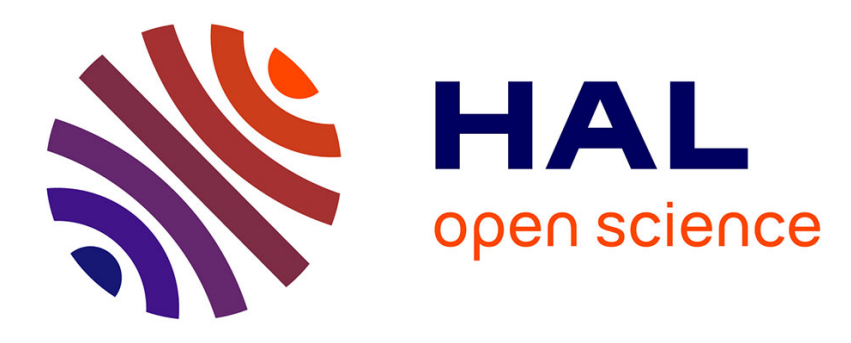

\title{
Consolidation settlement of a soil with an impervious top surface
}

\author{
Maurice A. Biot, F. M. Clingan
}

\section{To cite this version:}

Maurice A. Biot, F. M. Clingan. Consolidation settlement of a soil with an impervious top surface. Journal of Applied Physics, 1941, 12 (7), pp.578-581. 10.1063/1.1712940 . hal-01368645

\section{HAL Id: hal-01368645 https://hal.science/hal-01368645}

Submitted on 21 Sep 2016

HAL is a multi-disciplinary open access archive for the deposit and dissemination of scientific research documents, whether they are published or not. The documents may come from teaching and research institutions in France or abroad, or from public or private research centers.
L'archive ouverte pluridisciplinaire HAL, est destinée au dépôt et à la diffusion de documents scientifiques de niveau recherche, publiés ou non, émanant des établissements d'enseignement et de recherche français ou étrangers, des laboratoires publics ou privés. 


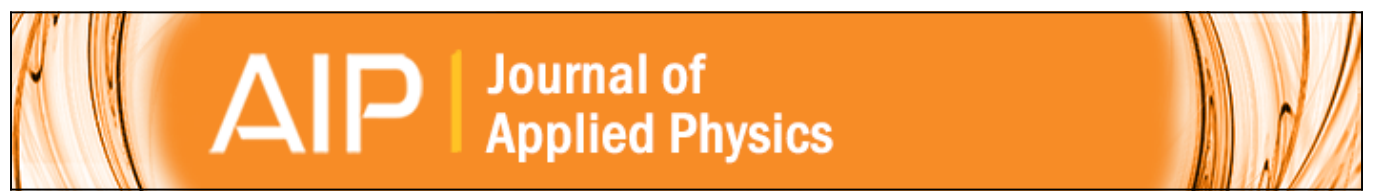

\section{Consolidation Settlement of a Soil with an Impervious Top Surface}

M. A. Biot and F. M. Clingan

Citation: Journal of Applied Physics 12, 578 (1941); doi: 10.1063/1.1712940

View online: http://dx.doi.org/10.1063/1.1712940

View Table of Contents: http://scitation.aip.org/content/aip/journal/jap/12/7?ver=pdfcov

Published by the AIP Publishing

\section{Articles you may be interested in}

Surface Sensing and Settlement Strategies of Marine Biofouling Organisms

Biointerphases 7, 63 (2012); 10.1007/s13758-012-0063-5

Nonlinear surface waves in soil

J. Acoust. Soc. Am. 120, 3281 (2006); 10.1121/1.4777399

Settlement behavior of swimming algal spores on gradient surfaces

Biointerphases 1, 18 (2006); 10.1116/1.2188520

Bending Settlement of a Slab Resting on a Consolidating Foundation

J. Appl. Phys. 13, 35 (1942); 10.1063/1.1714800

Consolidation Settlement Under a Rectangular Load Distribution

J. Appl. Phys. 12, 426 (1941); 10.1063/1.1712921

\section{High Energy Nanosecond Lasers}
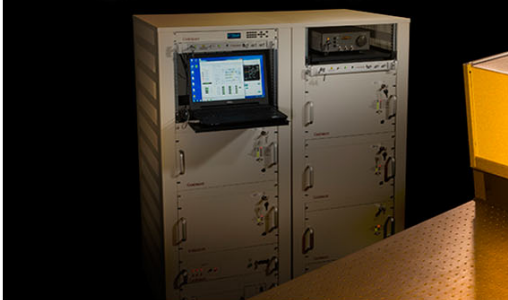
and the corresponding integrals

We finally have

$$
\int_{2}^{n-3} t \psi^{2}(t) d t \text { and } \int_{2}^{n-3} t^{2} \psi^{2}(t) d t
$$

$$
\begin{aligned}
& \sum_{j=2}^{n-2} j S_{1}(j+1)=\frac{(n-3)(n+2)}{4}-\psi(n-2)+\psi(1) \\
& \sum_{j=2}^{n-2} j^{2} S_{1}{ }^{(j+1)}=\frac{(n-2)(n-1)(4 n+3)}{36}+\frac{(n-8)}{6}-\psi(n-2)+\psi(1) .
\end{aligned}
$$

For the sake of brevity, the sums over $S_{2}^{(j+1)}$ have not been written down explicitly, but they can easily be found with the aid of the previous expressions.

Taking in our example $n=300$ we find for instance

$$
\sum_{j=2}^{n} N_{j}=N_{n}(0) e^{-\tau / 2}\left(1+0.997 \tau+0.488 \tau^{2}+0.143 \tau^{3}+O\left(\tau^{4}\right)\right)
$$

and similar equations for the other sums showing their relatively good convergence.

\title{
Consolidation Settlement of a Soil with an Impervious Top Surface
}

\author{
M. A. Biot and F. M. Clingan \\ California Institute of Technology, Pasadena, California
}

(Received April 8, 1941)

\begin{abstract}
An investigation is made of the consolidation settlement for a soil whose top surface is impervious and loaded uniformly on an infinite strip of constant width. The settlement under the load is accompanied by considerable swelling of the unloaded area on both sides of the load.
\end{abstract}

\section{INTRODUCTION}

$I^{\mathrm{s}}$ a previous publication ${ }^{1}$ the settlement of a consolidating soil under an area of constant width was obtained when the water is allowed to flow freely through the top surface both outside and under the load. We are going to investigate the same problem when the top surface is completely impervious both outside and under the load. It is clear that in this case the settlement is due to the fact that the water contained in the soil flows from under the load to unloaded regions. Since it is assumed that the water cannot escape through the top surface, this will produce a swelling of the unloaded area in the vicinity of the load. For the basic theory the reader is referred to a recent paper. ${ }^{2}$

\section{Settlement Under a LoAd with Sinusoldal Distribution}

In the previous paper ${ }^{2}$ have been established the following equations for the two-dimensional problem of the consolidation of completely satu-

1 M. A. Biot, "Consolidation settlement under a rectangular load distribution," J. App. Phys. 12, 426 (1941).

2 M. A. Biot, "General theory of three-dimensional consolidation," J. App. Phys. 12, 155 (1941). rated clay with zero Poisson ratio

$$
\begin{gathered}
G \nabla^{2} u+G \frac{\partial \epsilon}{\partial x}-\frac{\partial \sigma}{\partial x}=0, \\
G \nabla^{2} w+G \frac{\partial \epsilon}{\partial z}-\frac{\partial \sigma}{\partial z}=0 \\
\nabla^{2} \epsilon=p \epsilon / c .
\end{gathered}
$$

In these equations $u$ and $w$ are the components of the displacement of the soil, $\epsilon=\partial u / \partial x+\partial w / \partial z$; $G$ is the shear modulus for the completely consolidated clay ; $c=k / a$ coefficient of consolidation ; $k$ is the coefficient of permeability; $a=1 /(2 G)$ the final compressibility; $\sigma$ water pressure increment in the pores; $p=\partial / \partial t$ symbolic operator. These equations must be solved with the boundary conditions (1) that all variables vanish at infinite depth $z=\infty$; (2) $\partial \sigma / \partial z=0$ at $z=0$; (3) $-\sigma+2 G \partial w / \partial z=-A \sin \lambda x$ at $z=0$; (4) $\partial u / \partial z$ $+\partial w / \partial x=0$ at $z=0$. The second condition expresses that no water flows from the top surface.

The last two conditions express that at the surface the normal stress is equal to the load and that the shearing stress is zero. 
It may be verified that a solution of Eqs. (1.1) satisfying the boundary condition (1) is

$$
\begin{gathered}
u=\left[C_{1} \lambda e^{-\lambda z}+C_{2} \lambda \exp \left[-\left(\lambda^{2}+p / c\right)^{\frac{1}{2} z}\right]\right. \\
\left.-C_{3}(1-\lambda z) e^{-\lambda z}\right] \cos \lambda x, \\
w=\left[-C_{1} \lambda e^{-\lambda z}-C_{2}\left(\lambda^{2}+p / c\right)^{\frac{1}{2}}\right. \\
\times \exp \left[-\left(\lambda^{2}+p / c\right)^{\frac{1}{3} z}\right] \\
\left.-C_{3} \lambda z e^{-\lambda z}\right] \sin \lambda x, \\
\sigma=2 G\left[C_{2}(p / c) \exp \left[-\left(\lambda^{2}+p / c\right)^{\frac{1}{z} z}\right]\right. \\
\left.-C_{3} \lambda e^{-\lambda z}\right] \sin \lambda x,
\end{gathered}
$$

in which the arbitrary constants $C_{1}, C_{2}$ and $C_{3}$ are to be determined so that the remaining boundary conditions (2), (3) and (4) are satisfied. We find

$$
\begin{gathered}
(p / c) C_{2}\left(\lambda^{2}+p / c\right)^{\frac{1}{2}}-C_{3} \lambda^{2}=0, \\
2 G \lambda^{2}\left(C_{1}+C_{2}\right)=-A, \\
\lambda C_{1}+\left(\lambda^{2}+p / c\right)^{\frac{1}{2}} C_{2}-C_{3}=0 .
\end{gathered}
$$

We are interested in the vertical deflection $w$ at the surface, $z=0$. This value is from (1.2) and (1.3)

$$
\begin{aligned}
w=\left[-C_{1} \lambda-C_{2}\left(\lambda^{2}+p / c\right)^{1}\right] & \sin \lambda x \\
& =-C_{3} \sin \lambda x .
\end{aligned}
$$

Solving (1.3) for $C_{3}$ we obtain

$$
C_{3}=\frac{A}{2 G \lambda} \frac{\left(1+p / \lambda^{2} c\right)^{\frac{1}{2}}}{\left(\lambda^{2} c / p-1\right)\left(p / \lambda^{2} c+1\right)^{\frac{1}{1}}-\lambda^{2} c / p} .
$$

The soil deflection at the surface as a function of the time for a sudden sinusoidal load distribution is written in operational form

$$
w=\frac{A \sin \lambda x}{2 G \lambda} \frac{p^{2} / c^{2} \lambda^{4}-1-\left(1+p / c \lambda^{2}\right)^{\frac{1}{2}}}{p^{2} / c^{2} \lambda^{4}-p / c \lambda^{2}-1} .
$$

The function represented symbolically by this equation may be calculated from the following operational expressions.

$$
\begin{aligned}
& \frac{p^{2} / c^{2} \lambda^{4}}{p^{2} / c^{2} \lambda^{4}-p / c \lambda^{2}-1} 1(t)=\frac{\exp \left[\lambda^{2} c t / 2\right]}{5^{\frac{1}{2}}}\left[\sinh \left(\frac{5^{\frac{1}{2}}}{2} \lambda^{2} c t\right)+5^{\frac{1}{2}} \cosh \left(\frac{5^{\frac{1}{3}}}{2} \lambda^{2} c t\right)\right] . \\
& \frac{1}{p^{2} / c^{2} \lambda^{4}-p / c \lambda^{2}-1} 1(t)=\frac{\exp \left[\lambda^{2} c t / 2\right]}{5^{\frac{1}{2}}}\left[-\sinh \left(\frac{5^{\frac{1}{2}}}{2} \lambda^{2} c t\right)+5^{\frac{1}{2}} \cosh \left(\frac{5^{\frac{1}{2}}}{2} \lambda^{2} c t\right)\right]-1,
\end{aligned}
$$

$$
\begin{aligned}
\frac{\left(1+p / c \lambda^{2}\right)^{\frac{1}{2}}}{p^{2} / c^{2} \lambda^{4}-p / c \lambda^{2}-1} 1(t)=\frac{\exp \left[\left(1+5^{\frac{1}{3}}\right) \lambda^{2} c t / 2\right]}{5^{\frac{1}{2}}} P\left[\left(1+5^{\frac{1}{2}}\right) \lambda(c t)^{\frac{1}{2}}\right]-P\left[\lambda(c t)^{\frac{1}{2}}\right] & -\frac{\exp \left[\left(1-5^{\frac{1}{2}}\right) \lambda^{2} c t / 2\right]}{5^{\frac{1}{2}}} P\left[\left(1-5^{\frac{1}{2}}\right) \lambda(c t)^{\frac{1}{3}}\right] .
\end{aligned}
$$

The first two operators are tabulated ${ }^{3}$ while the third is derived by separation into partial fractions and applying the shifting formula ${ }^{4}$ to the well-known operator

$$
p^{\frac{1}{2}} 1(t)=\frac{1}{(\pi t)^{\frac{1}{3}}} .
$$

With these results the deflection at the soil surface is written

\footnotetext{
${ }^{3}$ E. Berg, Heaviside's Operational Calculus (McGrawHill Book Company, Inc., New York, 1929), p. 165.

${ }^{4} \mathrm{~V}$. Bush, Operational Circuit Analysis (John Wiley and Sons, New York, 1929), pp. 130, 191.
}

$$
\begin{aligned}
w & =\frac{A \sin \lambda x}{2 G \lambda}\left\{1+P\left[\lambda(c t)^{\frac{1}{2}}\right]\right. \\
& +\frac{\exp \left[\left(1+5^{\frac{1}{2}}\right) \lambda^{2} c t / 2\right]}{5^{\frac{1}{2}}}\left(1-P\left[\left(1+5^{\frac{1}{2}}\right) \lambda(c t)^{\frac{1}{2}}\right]\right) \\
& \left.-\frac{\exp \left[\left(1-5^{\frac{1}{3}}\right) \lambda^{2} c t / 2\right]}{5^{\frac{1}{2}}}\left(1-P\left[\left(1-5^{\frac{1}{3}}\right) \lambda(c t)^{\frac{1}{2}}\right]\right)\right\} .
\end{aligned}
$$

In these formulas we have

$$
P(x)=\frac{2}{\pi^{\frac{1}{2}}} \int_{0}^{x} \exp \left(-\xi^{2}\right) d \xi
$$




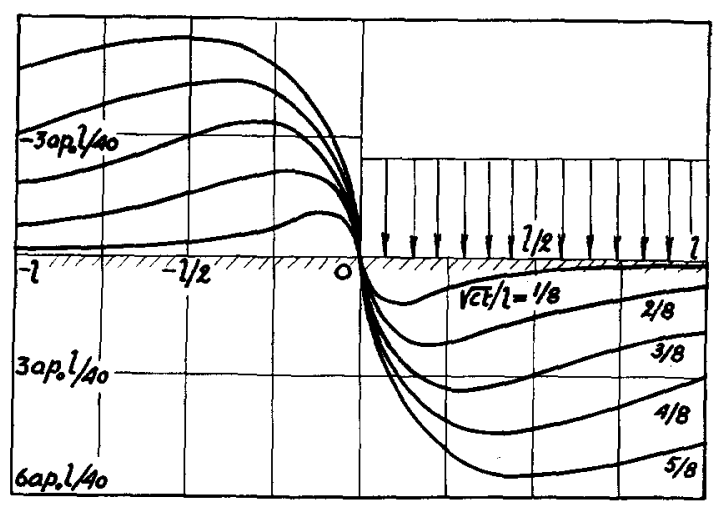

FIg. 1. Settlement of soil surface at various instants of time for a uniform load $p_{0}$ extending from $x=0$ to $x=\infty$.

a tabulated function called the probability integral.

The settlement is composed of two parts: a purely elastic deflection which occurs at the instant of application of the load and a settlement due to consolidation which occurs gradually thereafter. Since we are interested only in the latter we proceed as follows:

For $t=0$ the deflection is purely elastic, its value is

$$
w_{i}=A \sin \lambda x / 2 G \lambda \text {. }
$$

The settlement due to consolidation is

$$
w_{s}=w-w_{i}
$$

For convenience we will write Eq. (1.13) in the form

$$
w_{\mathrm{s}}=(a A / \lambda) F\left[\lambda(c t)^{\mathfrak{b}}\right] \sin \lambda x
$$

\section{Settlement Under a Uniform Load With Discontinuity}

For practical purposes we are interested in the differential settlement occurring when the load distribution has a discontinuity. Such a load distribution will be represented by the following function of $x$

$$
\varphi(x)=\frac{p_{0}}{\pi} \int_{0}^{\infty} \frac{\sin \lambda x}{\lambda} d \lambda
$$

in which case $\varphi(x)=-p_{0} / 2$ for $x<0, p_{0} / 2$ for $x>0$ with a discontinuity at $x=0$.

The settlement due to this load is obtained from (1.14) by the principle of superposition;

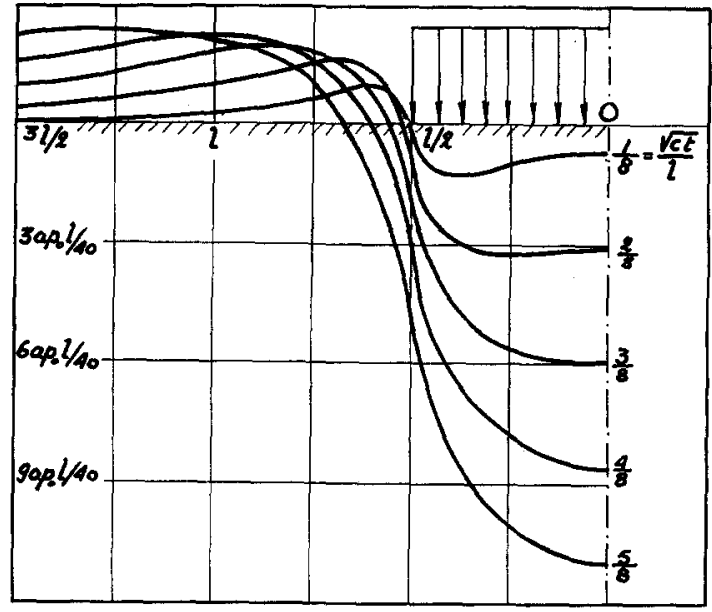

Fig. 2. Settlement of soil surface at various instants of time for a uniform load $p_{0}$ extending from $x=-l / 2$ to $x=+l / 2$.

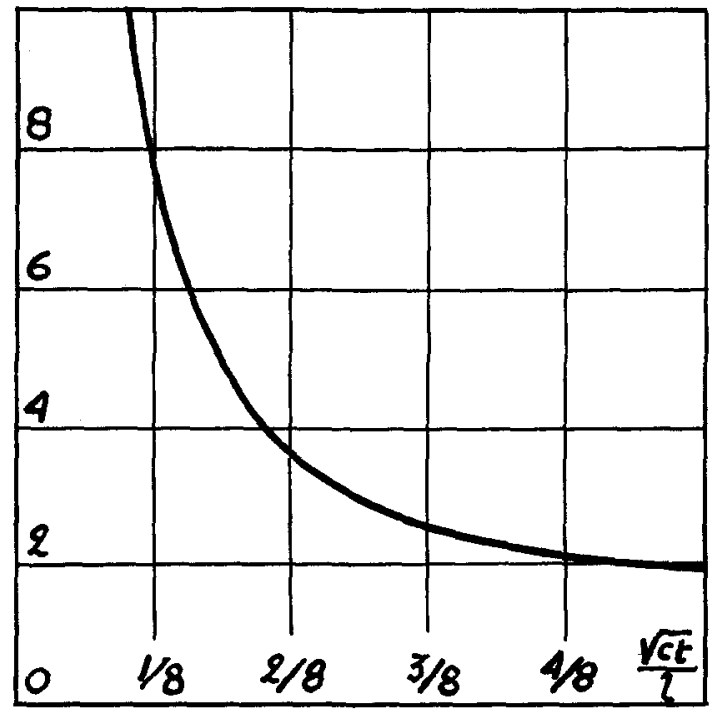

FIG. 3. Rates of the settlement at the center of the loaded area in Fig. 2 when the top surface is pervious to the settlement, when the top surface is impervious.

we find

$$
w_{s}=\frac{a p_{0}}{\pi} \int_{0}^{\infty} \frac{F\left[\lambda(c t)^{\frac{2}{2}}\right]}{\lambda^{2}} \sin \lambda x d \lambda,
$$

which can be written in the form

$$
\frac{w_{s}}{2 a p_{0}}\left(\frac{\pi}{c t}\right)^{\frac{1}{2}}=\frac{1}{2 \pi^{\frac{1}{2}}} \int_{0}^{\infty} \frac{F(\gamma)}{\gamma^{2}} \sin (\gamma \xi) d \gamma
$$

with $\xi=x /(c t)^{\frac{3}{3}}$. 
This integral can be evaluated numerically by the use of an approximate analytical expression for the function $F(\gamma)$. It may be verified that this function is represented within 2 percent by

$$
\begin{aligned}
F(\gamma)=1-e^{-\gamma}-\gamma e^{-2 \gamma}-1.06 \gamma^{2} e^{-3 \gamma} & \\
& +0.28 \gamma^{2} e^{-1.2 \gamma} .
\end{aligned}
$$

If (2.3) is integrated with the substitution (2.4) we find

$$
\begin{gathered}
\frac{w_{s}}{2 a p_{0}}\left(\frac{\pi}{c t}\right)^{\frac{1}{2}}=\frac{1}{4 \pi^{\frac{1}{2}}} \xi \log \left(1+\frac{1}{\xi^{2}}\right)+\frac{1}{2 \pi^{\frac{1}{2}}} \tan ^{-1} \xi \\
-\frac{1}{2 \pi^{\frac{1}{2}}} \tan ^{-1} \xi / 2-\frac{1.06 \xi}{2 \pi^{\frac{1}{2}}\left(9+\xi^{2}\right)}+\frac{0.28 \xi}{2 \pi^{\frac{1}{2}}\left(1.44+\xi^{2}\right)}
\end{gathered}
$$

By adding a load equal to $p_{0} / 2$ and extending from $x=-\infty$ to $x=+\infty$ we obtain a total uniform load extending from $x=0$ to $x=\infty$ as shown in Fig. 1. In doing so we do not change the settlement because the water is imprisoned in the soil by the impervious layer at the surface and therefore a load extending from $x=-\infty$ to $x=+\infty$ cannot produce any settlement. Hence the settlement for the load $p_{0}$ extending over the positive $x$ axis is given by the same expression (2.5) which we write

$$
w_{s}=2 a p_{0}(c t / \pi)^{\frac{3}{3}} f(\xi),
$$

where $f(\xi)$ denotes the right-hand side of Eq. (2.5). It is clear that the volume of the water in the soil being constant, the total area under the curve $f(\xi)$ is zero.

In order to represent the settlement as a function of time it is convenient to introduce for the abscissa a characteristic length $l$ which can be chosen arbitrarily. We then have

$$
w_{s}=\frac{2}{\pi^{\frac{1}{2}}} a p_{0} l \frac{(c t)^{\frac{1}{2}}}{l} f\left[\frac{x}{l} \frac{l}{(c t)^{\frac{1}{2}}}\right] .
$$

Then settlement curves are plotted as function of $x$ in Fig. 1 at time intervals corresponding to $(c t)^{\frac{1}{2}} / l=1 / 8,2 / 8,3 / 8,4 / 8,5 / 8$.

\section{Settlement Under a Rectangular LOAD Distribution}

By superposition we may easily derive from the previous solution the settlement due to a constant load $p_{0}$ extending from $x=-l / 2$ to $x=l / 2$. Using (2.6) we get

$w_{s}=\frac{2}{\pi^{\frac{1}{2}}} a p_{0} l \frac{(c t)^{\frac{1}{2}}}{l}\left[f\left(\frac{x+l / 2}{(c t)^{\frac{1}{3}}}\right)-f\left(\frac{x-l / 2}{(c t)^{\frac{1}{2}}}\right)\right]$.

The settlement curves are represented in Fig. 2 as a function of $x$ at time intervals corresponding to $(c t)^{t /} / l=1 / 8,2 / 8,3 / 8,4 / 8,5 / 8$.

It will be noted that immediately after loading the settlement at the edge is greatly affected by the unloaded section adjacent to it. This unloaded section provides an escape for the water which is not as readily available for the water under the center of the load. Also since this load and deflection are symmetrical to the line $x=0$ no water will flow across this line and therefore the area under the curve from 0 to $\infty$ must be equal to zero.

If the ratio of the deflection at $x=0$ is compared with the case in a previous paper ${ }^{2}$ in which the loading is the same but the water was allowed to flow freely from the top surface the effect of an impervious top surface will be seen. This comparison is made in Fig. 3. 